\title{
Introduction to Intellectual Property as a Complex Adaptive System
}

\section{Anselm Kamperman Sanders and Anke Moerland}

Drawing on the experience and research carried out as part of the EU-funded EIPIN Innovation Society project, ${ }^{1}$ this volume in the EIPIN book series assembles contributions that discuss the role of intellectual property (IP) rights on innovation. We analyze how complex IP rule systems benefit innovation processes, how actors collaborate in these new ecosystems and in how far adequate checks and balances are in place to foster creativity and innovation.

The book is structured according to three main areas. The first part of the book concentrates on patents and discusses how patent pools, standard-setting organizations and the Unified Patent Court system contribute to innovation, fulfil distribution needs and are in line with competition law rationales. In light of AI assisting or, in the future, generating inventions, we also examine the necessity to change the inventive step test in patent law.

In Chapter 1, Anselm Kamperman Sanders and Anke Moerland provide an embedding for the other chapters of the book. The chapter illustrates what the characteristics of complex adaptive systems (CAS) are and how they apply to intellectual property rights. This new perspective of understanding IP protection as non-linear and based on interaction between actors helps to address the problem of Valley of Death. This problem entails that many inventions developed in the laboratory or research institutes are not brought to the market, arguably due to the complex relationships that lie at the heart of innovation. Chapter 1, in this sense, provides the basis for the other contributions to develop specific aspects of the complexity further.

In Chapter 2, David A. Harper places IP at the core of the connective structure of rules that supports production and exchange in the knowledge economy. In applying the CAS approach, he highlights the role of IP in capital formation, exemplifying the way in which entrepreneurs collaborated to create the MPEG-2 patent pool.

1 EIPIN Innovation Society, <www.eipin-innovationsociety.org $>$ accessed 1 March 2021. 
This contribution is followed in Chapter 3 by that of Christof Augenstein, who emphasizes the importance of patent protection of technical inventions compared to protection by trade secrets only, and ties this to the needs of patentees in the context of the future Unified Patent Court.

The CAS aspects of network connectivity are covered in Chapter 4 by Beatriz Conde Gallego, with a forward-looking exposé on the Internet of Things (IoT). Since a growing number of market actors will make use of this technology, the complexity of licensing of standard essential patents (SEPs) is likely to increase. Conflicts are thus almost inevitable. The chapter explores the theoretical framework for the licensing of SEPs in the IoT context, highlights the difficulties that it could encounter in practice and proposes ways for its implementation. This, then, segues into the interface between IP and competition policy.

The contribution in Chapter 5 by Marco D'Ostuni analyzes how the ever-increasing number of patents (applied for and granted) and the new strategies deployed by companies in response to this increasing number tested the traditional principles developed by the EU Court of Justice and by the EU Commission's decision-making practice in cases found at the intersection between patent and competition law.

The first part is concluded in Chapter 6 by Ryan Abbott who covers the vexing issue of the man-machine relationship. He assesses the question of whether the inventive step criteria will need to be adapted to the role AI already plays and will play in the future in research and development of inventions. Where inventors are assisted, or at one time replaced, by machines, their knowledge is becoming more sophisticated and elaborate. The traditional test as to whether an invention is obvious to a person skilled in the art may then no longer reflect the actual knowledge of the machine-assisted inventor or, in the future, the machine. Abbott therefore argues that the new test should make it more difficult to obtain a patent because more will be obvious to a machine-assisted inventor or a sufficiently knowledgeable machine.

The second part of the book takes an incentive approach and focuses on how to foster creativity and collective management in two distinct markets. We provide insights into how the regulation of certain markets, in particular agricultural products and the online market for music, can contribute to an environment where creativity takes place and collective management of producers is stimulated, leading to innovative practices.

Andrea Zappalaglio discusses in Chapter 7 the EU sui generis system for the protection of geographical indications (GIs), and in particular what the very nature of this system is. He describes that the system of geographical indications constitutes a complex system where heterogeneous actors interact and undertake collective behaviour in order to agree on the specific characteristics of an agricultural product. Preserving the link between the product 
and its origin is a key characteristic of the system; in order to guarantee this, and to allow for innovative practices to take place, producers need to engage in collective management. The system, therefore, has a bureaucratic structure that involves public authorities in the application and enforcement stage.

The online market for music clearly differs from that of agricultural products protected by geographical indications. Giuseppe Mazziotti's Chapter 8 assesses how EU law fosters innovation in the current music marketplace. The EU's vision is that regulation seeks to ensure that cultural diversity and European content productions can thrive on the grounds of contractual fairness, transparency and proportionate remuneration of individual creators. By focussing on the dominant (and distinct) functions and business models of on-demand music services and social media, Mazziotti questions whether the current licensing activities meet these standards.

The third part of the book presents an institutional approach. It offers a different perspective to IP law-making by judicial bodies, in particular investorstate tribunals. In the final Chapter 9, Rochelle Cooper Dreyfuss addresses the question as to whether tribunals that entertain investor-state disputes under bilateral and regional investment agreements contribute to the development of intellectual property law. It answers the question in the negative, arguing that to the extent these tribunals "make" law, the laws they make constrain the evolution of intellectual property-related lawmaking. Exemplified by the slower than necessary government response to, inter alia, the COVID-19 pandemic, the risk of a chilling effect brought on by the risk of investor lawsuits is all too real. The chapter considers whether newer instruments, which are intended to be more protective of sovereignty, in fact give states the freedom they require to keep intellectual property responsive to society's needs. 
Anselm Kamperman Sanders and Anke Moerland - 9781800378384 Downloaded from PubFactory at 04/26/2023 10:49:09AM 